\title{
Competitive interference of plant species in monocultures and mixed stands
}

\author{
K. Baeumer ${ }^{1}$ and C. T. de Wit \\ Faculty of Agriculture, University of Göttingen, Germany; \\ Institute for Biological and Chemical Research on Field Crops and Herbage (I.B.S.), \\ Wageningen, The Netherlands
}

Received 20 December, 1967

\section{Summary}

A dynamic model has been developed enabling to calculate the dry matter yields of species in a mixture on the $(n+1)$-th day from the dry matter yields on the $n$-th day by means of parameters derived from a spacing experiment with the species at two densities, harvested at intervals. Differences of growth in height between the species are taken into account. The model is evaluated by means of experiments with oats, barley, long peas and short peas. It is assumed to be applicable under conditions of near optimum supply with water and nutrients, i.e. under conditions where the species mainly interfere by competition for light.

The analogies and differences with the Volterra-equations used in animal ecology are discussed. A simple non-destructive method for measuring the relative light interception of species in mixed stands is described also.

\section{Introduction}

A theory on plant competition, aiming at an analysis of general principles by using models, suitable for quantitative treatment and formal interpretation of many competition phenomena, was introduced by De Wit and Ennik (1958) and worked out in more detail by De Wit (1960), De Wit and Van den Bergh (1965) and Tow, Ennik and De Wit (1966).

It was shown that results of spacing experiments with a species in monoculture could be treated with equations derived from a model valid in case of more than one species competing for the same space. Within limits it should be possible therefore to predict the yield of two or more species in mixed cultures from their yield in monoculture with varied spacing.

In the following paper this hypothesis will be examined. Based on a further elaboration of the theory and on the results of several field experiments with oats, barley and peas, the possibilities and limitations of this concept will be discussed. In addition a simple method will be described which has been developed to measure the

1 With support of the Deutsche Forschungsgemeinschaft, Bad Godesberg, Germany, which financed a sabbatical year of the author, spent at the Institute for Biological and Chemical Research on Field Crops and Herbage (I.B.S.), Wageningen, The Netherlands. 
relative light interception of one species with regard to the other species grown in the mixture. This method has been applied to collect some data on the interference between oats and peas which was supposed to be the result of competition for light.

\section{Influence of sowing density on yield in dependence on age}

The yield of a plant species sown in monoculture depends on plant density and the length of the growing period. At earlier stages or within low density ranges, the yield is almost proportional to plant density, but later on and at higher plant densities a maximum yield will be approached. Thus yield as a function of density happens to follow a type of saturation curve, as illustrated in Fig. 1. According to various authors (Shinozaki and Kira, 1956, De Wit, 1960, Holliday, 1960) this relation may be presented within a wide range of densities by:

$$
\mathrm{O}=\frac{\beta \mathbf{Z}}{\beta \mathbf{Z}+\mathbf{1}^{-} \Omega}
$$

where $\mathrm{Z}$ is the density of sowing or planting in for instance plants $/ \mathrm{m}^{2}, \mathrm{~kg}$ seed $/ \mathrm{ha}$ or rows $/ \mathrm{cm}$ and $O$ is the yield in $\mathrm{kg}$ seed/ha or $\mathrm{kg}$ dry matter/ha. The parameters $\beta$ and $\Omega$ are constant functions of the density, $\Omega$ being the maximum yield to be obtained at high densities and $\beta$, expressed in the inverse unit of the seed rate, characterizing the degree of saturation. The yield increases almost proportional to the seed rate when $\beta \mathbf{Z}$ is small compared to 1 and is almost independent of the seed rate when $\beta \mathbf{Z}$ is large compared to 1 .

The extrapolated yield of a single plant or row of plants in the absence of any interference of neighbours is given by the product $\beta \Omega$ as appears from dividing the yield $O$ by the seed rate $Z$ and taking the limit for $Z$ approaching zero:

$\operatorname{Lim}_{z \rightarrow 0}\left(\frac{\mathrm{O}}{\mathrm{Z}}\right)=\operatorname{Lim}_{z \rightarrow 0}\left(\frac{\beta \Omega}{\beta \mathrm{Z}+1}\right)=\beta \Omega$

in $\mathrm{kg} /$ plant or $\mathrm{kg} /$ row.

The space occupied by a single plant under these conditions is equal to $\beta$ as can be shown by dividing the yield $O$ by $Z$ and $\Omega$ and taking the limit for $Z$ approaching zero:

$\operatorname{Lim}_{z \rightarrow 0}(\bar{Q} \bar{Z})=\operatorname{Lim}_{z \rightarrow 0}\left(-\frac{\beta}{\beta z+1}\right)=\beta$

in $\mathrm{cm}^{2} /$ plant or $\mathrm{cm} /$ row.

Although $\beta, \Omega$ and $\beta \Omega$ are constant functions of density, they are not constant functions of time. During earlier stages and then in the whole practical range of sowing densities the yield is almost proportional to the seed rate, so that $\beta$ is practically zero and the product $\beta \Omega$ very small. Under these conditions the value of $\beta$ is indeterminable unless experiments with very high plant densities are done. Both $\beta$ and $\beta \Omega$ increase with increasing age until finally there is a situation, in which all the 


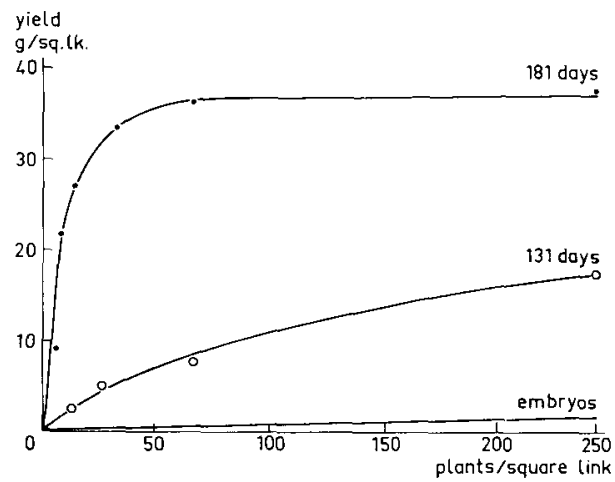

Fig. 1 Trifolium repens: yield in dependence of plant density and time. After Donald (1963).

yields are practically equal to the maximum yield. The value of $\beta$ then is high, but practically indeterminable, unless the seed densities are very low.

The time-curves of $\beta$ and $\beta \Omega$ can be calculated by means of eq. (1) from the yield data of a spacing experiment with two densities, harvested at successive times. A spacing experiment has been carried out with the species barley, oats, short peas and long peas, the planting densities being .04 rows $/ \mathrm{cm}(25 \mathrm{~cm} /$ row $)$ and $.01 \mathrm{rows} / \mathrm{cm}$ $(100 \mathrm{~cm} /$ row $)$. The experiment is reported in appendix 1 . The dependence of the parameter $\beta$ and $\beta \Omega$ on time for the four species under these conditions are shown in Fig. $2 a$ and $b$. The curves of $\beta \Omega$ or the calculated yields per row when grown wide apart are similar for the species, the yields increasing according to expectation more or less exponentially with time. The curves of $\beta$ or the space occupied by a single row, when grown wide apart, are not similar for the species. In case of barley, $\beta$ increases at first rapidly, but remains constant during the second half of the growing period, although the value of $\beta \Omega$ and therefore of $\Omega$ continues to increase. For peas, $\beta$ increases slowly at first, but continues to increase at an age, when the curve for barley already flattens. This difference may be associated with well known characteristics of the species. Barley already tillers at relatively low temperatures in spring, whereas peas in general are unable to do so. However, during the generative phase

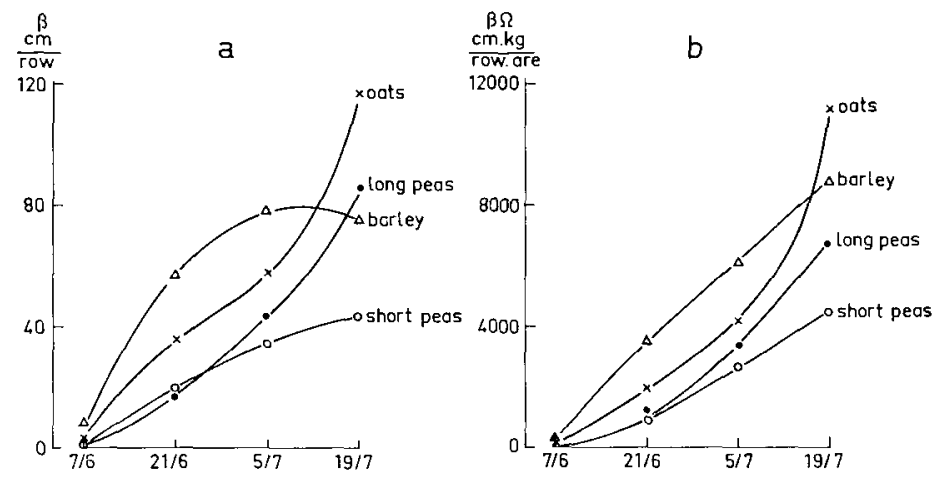

Fig. 2 Time dependent curves of $\beta(a)$ and $\beta @(b)$ for four species. Field experiment 1966. 
barley normally stops new tiller formation, whereas peas continue to form more nodes with leaves and axial flowers. Oats need higher temperatures for tillering than barley, but do not stop tillering as early as barley. Especially at low plant densities oats continue tillering during a prolonged period of the generative phase, a character, which has its drawback in practice.

\section{Competitive interference of barley and oats}

When grown in competition, barley clearly has the advantage over oats. It is able to claim the available space at an earlier stage, so that by the time the oats are able to claim their share, a disproportionate part of the space is already occupied by barley. It is necessary therefore to rearrange equation (1) in a somewhat unusual way to account for this phenomenon in a quantitative way. The relation between yield and density on an arbitrary day, $t$, is:

$\mathrm{O}_{\mathrm{t}}=\frac{\beta_{\mathrm{t}} \mathrm{Z}}{\beta_{\mathrm{t}} \mathrm{Z}+1} \Omega_{\mathrm{t}}$

The added indices, $t$, denote that all variables, except the seed rate $Z$, are time dependent. Since $\beta_{\mathrm{t}}$ is the absolute space occupied by one plant or one row or plants (compare equation 3), grown wide apart, the quotient:

$\frac{\mathrm{O}_{\mathrm{t}}}{\Omega_{\mathrm{t}}}=\mathrm{o}_{\mathrm{t}}=\frac{\beta_{\mathrm{t}} \mathrm{Z}}{\beta_{\mathrm{t}} \mathrm{Z}+1}$

may be termed the relative space occupied by the crop. This relative space, $o_{c}$, varies from zero at very wide plantings to one at very dense plantings. The yield of the crop varies between zero and the maximum yield $\Omega_{\mathrm{t}}$ according to:

$\mathrm{O}_{\mathrm{t}}=\mathrm{o}_{\mathrm{t}} \Omega_{\mathrm{t}}$

Equation (5) is now rearranged with $\mathrm{Z}$ explicit:

$\mathrm{Z}=-\frac{\mathrm{o}_{\mathrm{t}}}{\beta_{\mathrm{t}}\left(1-\mathrm{o}_{\mathrm{t}}\right)}$

and this value of $\mathrm{Z}$ is substituted in

$\mathrm{o}_{\mathrm{t}+1}=\frac{\beta_{\mathrm{t}+1} \mathrm{Z}}{\beta_{\mathrm{t}+1} \mathrm{Z}+1}$

which is the relation between relative space and density one day later. After some rearrangements this gives:

$o_{t: 1}=-\frac{\beta_{t} t^{1}}{\left(\beta_{t+1}-\beta_{t}\right)} o_{t}+\beta_{t}^{--} \cdot o_{t}$

This equation shows that, in dependence of the values of $\beta$ on day $\mathrm{t}$ and $(\mathrm{t}+1)$, 106 
the relative space occupied by the species at time $(t+1)$ is related to this space at time $t$.

There are two ways to calculate the relative space on the $(t+1)$-th day. At first the values of $\beta$ can be read from the graphs in Fig. $2 \mathrm{a}$ for the appropriate day and substituted in equation (4) with the proper value of $\mathrm{Z}$. The other way is to give an initial value for the relative space on the first day, read the values of $\beta$ on the first and second day, substitute these values in equation (8) and calculate the relative space, occupied on the second day. This procedure can then be repeated to calculate the relative space, occupied on the third, and following days until the $\mathrm{n}$-th day. This step by step advancing in time or simulating seems very cumbersome, but it is the only way in which to calculate the interference of two different plants species.

To introduce a second plant species, it must be realized, that the denominator in equation (8) characterizes the degree of intraspecific competition. At earlier stages o is so small, that the product $\left(\beta_{\mathrm{t}+1}-\beta_{\mathrm{t}}\right) \mathrm{o}_{\mathrm{t}}$ is small compared with $\beta_{\mathrm{t}}$, intraspecific competition is absent then and the relative space at time $(t+1)$ may be calculated from this space at time $\mathrm{t}$ by means of the simple relation: $o_{\mathrm{t}+1}=\left(\beta_{\mathrm{t}+1} \cdot \beta_{\mathrm{t}}^{-1}\right) \mathrm{o}_{\mathrm{t}}$ However, the importance of the term with $o$ in the denominator increases with time and, when o approaches 1 , relation (8) degenerates into $o_{t+1}=o_{t}$, so that 1 is the limiting value for $o$ : the intraspecific competition being then at full force.

Now it is assumed that there are two species feeling each others presence in the same way as their own. In that case the interspecific competition can be accounted for by adding the relative space occupied by the second species at time $t$ to the relative space occupied by the first species in the term $\left(\beta_{\mathrm{t}+1}-\beta_{\mathrm{t}}\right) \mathrm{o}_{\mathrm{t}}$, so that the relative space at time $(t+1)$ for the first species is given by:

$\mathrm{o} 1_{\mathrm{t} \div 1}=\frac{\beta 1_{\mathrm{t}+1}}{\left(\beta \mathbf{1}_{\mathrm{t}+1}-\bar{\beta} 1_{\mathrm{t}}\right)\left(\mathrm{o} 1_{\mathrm{t}}+\overline{\mathrm{o} 2}\right)+\beta 1_{\mathrm{t}}} \cdot \mathrm{o} 1_{\mathrm{t}}$

and for the second species by:

$\mathrm{o} 2_{\mathrm{t}+1}=\frac{\beta 2_{\mathrm{t}}+1}{\left(\beta 2_{\mathrm{t}+1}-\beta 2_{\mathrm{t}}\right)\left(\mathrm{o} 2_{\mathrm{t}}+\mathrm{o} 1_{\mathrm{t}}\right)+\beta 2_{\mathrm{t}}} \cdot \mathrm{o} 2_{\mathrm{t}}$

Obviously, when the sum of the relative spaces is 1 , neither of the species is able to occupy more space, implying that the species cannot encroach upon each other or in other words, that space once occupied cannot be released.

The interference of the two species barley and oats, grown in alternate rows $25 \mathrm{~cm}$ apart can now be calculated from the curves in Fig. 2. Three weeks after emergence on the 7 th of June there is negligible competition between the rows, so that the relative space occupied by barley in the mixture can be calculated by substituting 0.02 rows $/ \mathrm{cm}(50 \mathrm{~cm} /$ row $)$ for the seed density and $8.33 \mathrm{~cm} /$ row for $\beta$ in equation (4). This gives a valuue of 0.14 for o. In the same way it is found that the relative space occupied by oats on this date is only 0.05 . By substituting these values of $o$ and the values of $\beta$, as read from the graph in Fig. $2 \mathrm{a}$ on the 7 th and 8 th of June, into equation (9a), it is found that the relative space occupied by barley on the 8th of June is equal to 0.21 . Likewise it is found, that the relative space occupied by oats on the 8 th June is 0.11 . By repeating this procedure the relative space is found for both species on the 9 th, 10th of June and so on, up to the 19th of July. 


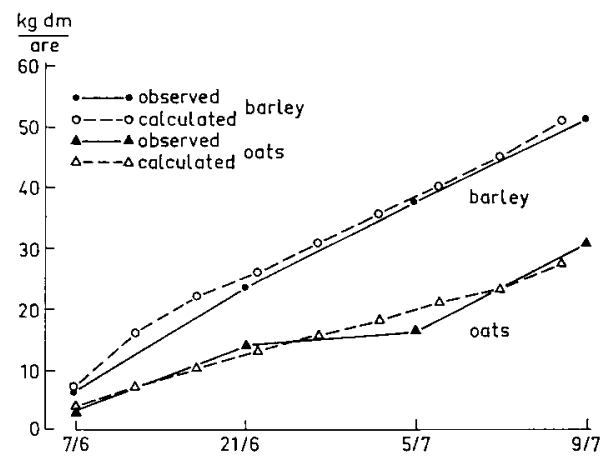

Fig. 3 Calculated (eq. 9) and observed yields of barley and oats in the mixture. Field experiment 1966.

By means of equation (6) and the values of $\Omega$ calculated from graphs a and $\mathrm{b}$ in Fig. 2, it is then possible to calculate the yield of two species during the course of time. The calculations are conveniently done by a computer.

The yield courses obtained in this way are presented in Fig. 3 by the broken lines. The two fully drawn lines show the yield courses as observed on a field with the two species sown in mixture as described in appendix 1 . The calculated and observed yield courses are in good agreement, showing that at least under the conditions prevailing in this experiment the two species feel each others presence in the same way as their own, according to the simple scheme presented by equation (9).

Hence, with these two species it is possible to estimate the competitive interference of two species or the interspecific competition from their performance in monoculture. Because the curves for $\beta$ of these two species are not similar, it is necessary to harvest the spacing experiment at suitable intervals. However, when two species or two varieties of one species are so alike that the curves of $\beta$ are similar, i.e. when the quotient $\beta 1 / \beta 2$ is a constant function of time, it is possible to calculate the result of the interspecific competition only from a final harvest of the spacing experiments. This is shown by considering the Relative reproductive or Replacement Rate as introduced by De Wit (1960) and De Wit and Van den Bergh (1965). This value is defined with:

$\operatorname{RRR}=\begin{aligned} & o 1_{t}+1 / o 1_{t} \\ & 02 t_{t}+1 / o 2_{t}\end{aligned}$

If the equation (9) holds, i.e. in the barley-oats situation of the present experiment, this works out to be:

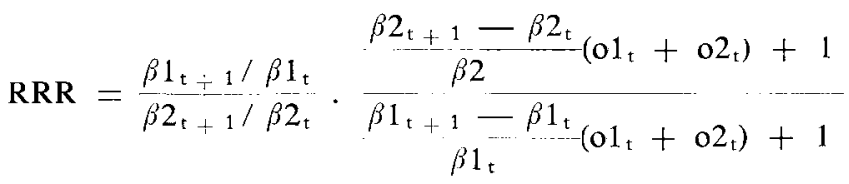

Hence, this value varies with the sum $o 1+o 2$ and because this sum increases with time, the value of RRR varies with time too. When the curves of $\beta$ for both species are similar, i.e. when the relative changes of $\beta$ are the same, that is:

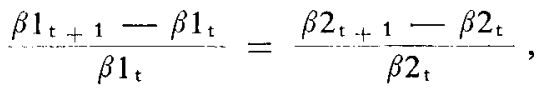


equation (11) is reduced to:

$\mathbf{R R R}=\frac{\beta 1_{\mathrm{t}+1} / \beta \mathbf{1}_{\mathrm{t}}}{\beta 2_{\mathrm{t}+1} / \beta 2_{\mathrm{t}}}$

Only under these conditions RRR is a constant function of time and of the initial sowing rates. Only then the yield at time $t$ can be directly calculated from the initial seed rates and the results of a spacing experiment with the two species harvested at time $t$ with:

$\mathrm{O} 1_{\mathrm{t}}=\frac{\beta 1_{\mathrm{t}} \mathrm{Z} 1}{\beta 1_{\mathrm{t}} \mathrm{Z} 1+\beta 2_{\mathrm{t}} \mathrm{Z} 2+1} \Omega 1_{\mathrm{t}}$

$\mathrm{O} 2_{\mathrm{t}}=\frac{\beta 2 \mathrm{t} Z 2}{\beta 2_{\mathrm{t}} \mathrm{Z} 2+\beta 1 \mathrm{t} \mathrm{Z} 1+1} \cdot \Omega 2_{\mathrm{t}}$

as discussed by De Wit (1960, page 60).

\section{Competitive interference of oats, short peas and long peas}

The experiment described in appendix 1 also involved treatments in which oats, long peas and short peas were grown in any two combinations in alternate rows of $25 \mathrm{~cm}$ distance. Any complications from nitrogen transfer of peas to oats were absent. In the first place, peas do not fix much nitrogen and in the second place a rather liberal supply of nitrogen suppressed any possible effect as is shown by the nitrate-content of oats at the time of heading. In dense monoculture, oats contained $0.22 \%$, in combination with barley $0.36 \%$ and in combination with short peas $0.38 \% \mathrm{NO}_{3}$ in the dry matter. With some nitrogen transfer a higher content of oats in combination with peas could be expected, but this did not occur. The long peas, in monoculture as well as in mixed culture were allowed to climb up a wire gauze of $1.20 \mathrm{~m}$ height.

The observed yield courses in the mixtures and the yield courses calculated by means of equation (9) are presented in Fig. $4 a, b$, and $c$ by full and broken lines, respectively. The agreement between the calculated and observed yields is poor, especially for the mixture of long and short peas. Hence, these species do not feel each others presence in the same way as their own, due to a more complicated interference below ground or above ground. To get some information about the nature of this interference, an experiment was carried out in the greenhouse in which long and short peas were grown in monoculture and in mixture with and without vertical partitions of the root system (see appendix 2). The results in Fig. 5 show that the competitive influence on each other is the same in both cases, whether the root systems are partitioned or not. Thus it can be concluded, that the interference was mainly above ground.

The heights of the crops in monoculture are shown in Fig. 6 for all four species concerned. Barley and oats follow about the same pattern throughout the season ending up with a length of about $90 \mathrm{~cm}$, so that one species did not overgrow the other. The height of the short peas did not exceed $40 \mathrm{~cm}$, whereas the long peas 

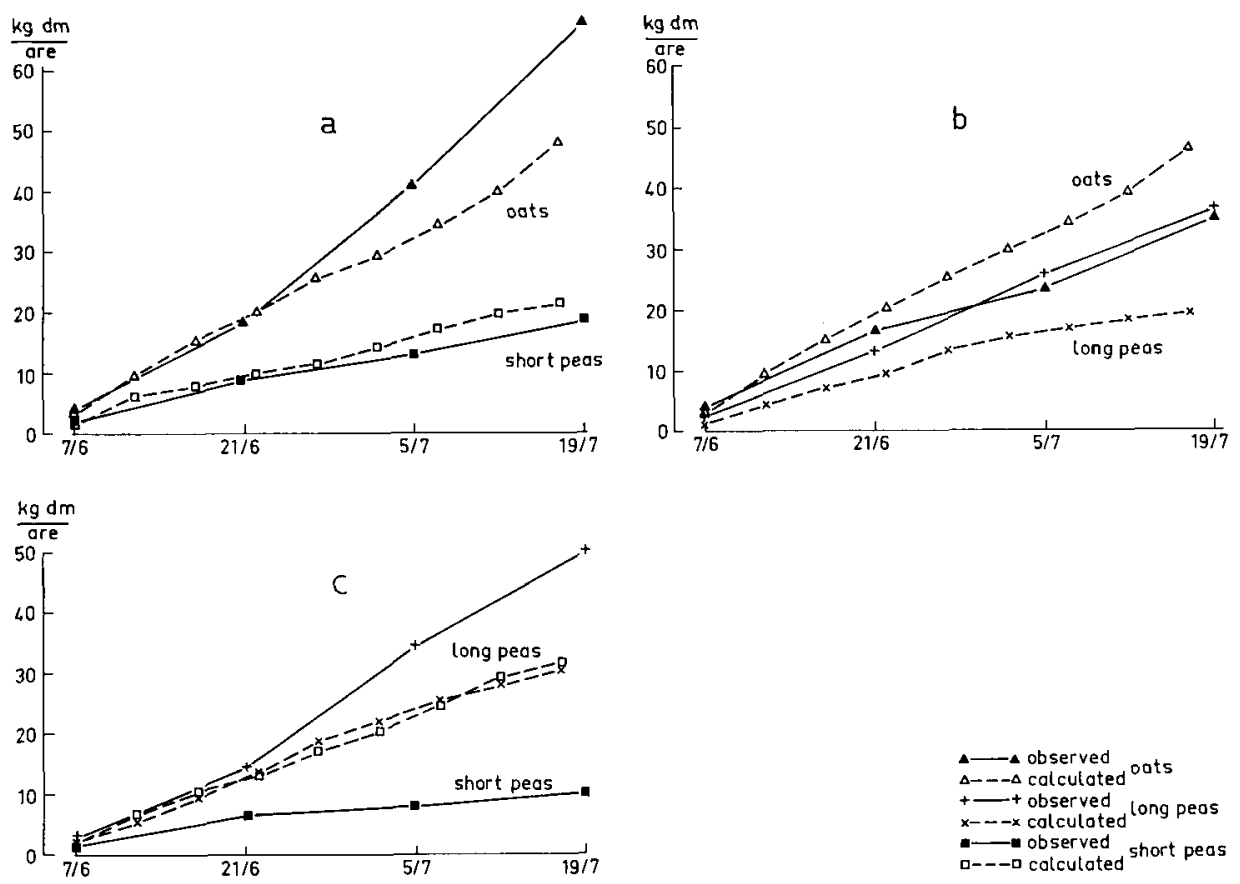

Fig. 4 Calculated (eq. 9) and observed yields of oats, short peas and long peas in mixtures. Field experiment 1966.

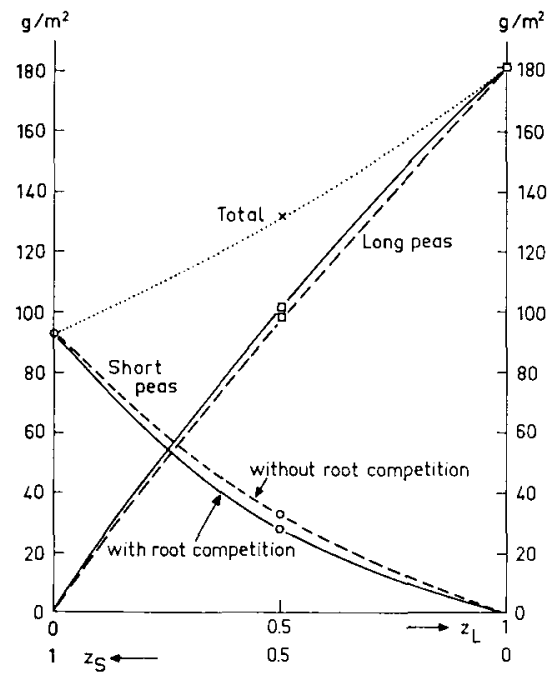

Fig. 5 Yield of long peas and short peas in mono-culture and mixture (alternate rows). Greenhouse experiment 1966. 


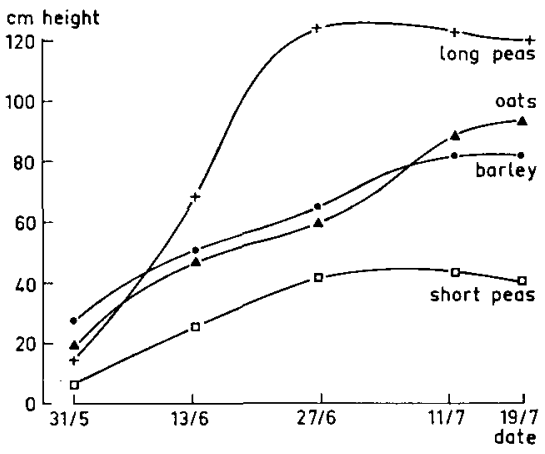

Fig. 6 Time dependent curves for the height of four species in monoculture, planted at 25 $\mathrm{cm}$. Field experiment 1966.

grew to an height of $120 \mathrm{~cm}$. It stands therefore to reason that in mixtures of long peas, short peas and oats the longer one encroaches up on the space once occupied by the shorter one. That this is indeed the case has been shown by measuring the percentage of light interception by each species grown in mixture. It suffices here to present the results, the method of measurement being discussed in appendix 3 .

The curves in Fig. 7a present the light interception by the mixture of barley and oats and by the individual components. As expected, the percentage of light intercepted by the mixture, as a whole, increased during the earlier stages of growth to about 90 percent and stayed at this value for the rest of the growing period. At the same time barley increased its interception to nearly 50 percent and oats to about 40 percent. These percentages stayed almost the same during the later growth stages,
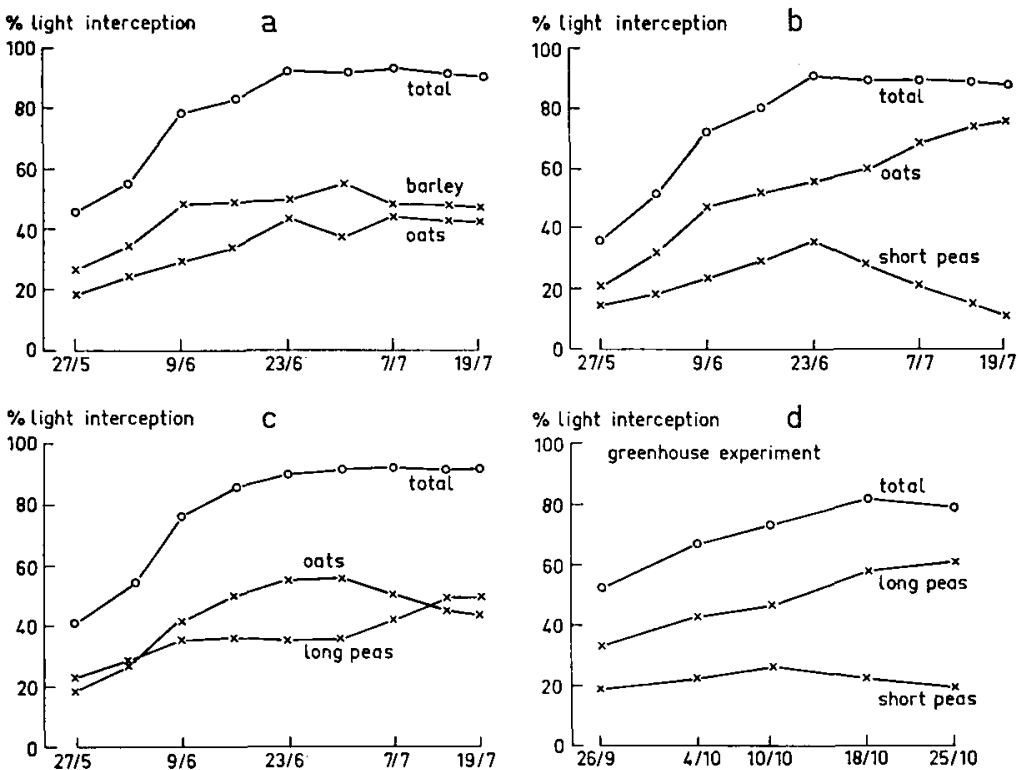

Fig. 7 Percentage relative light interception (RLI) of four species in the mixtures. Field experiment 1966. Greenhouse experiment 1966. 

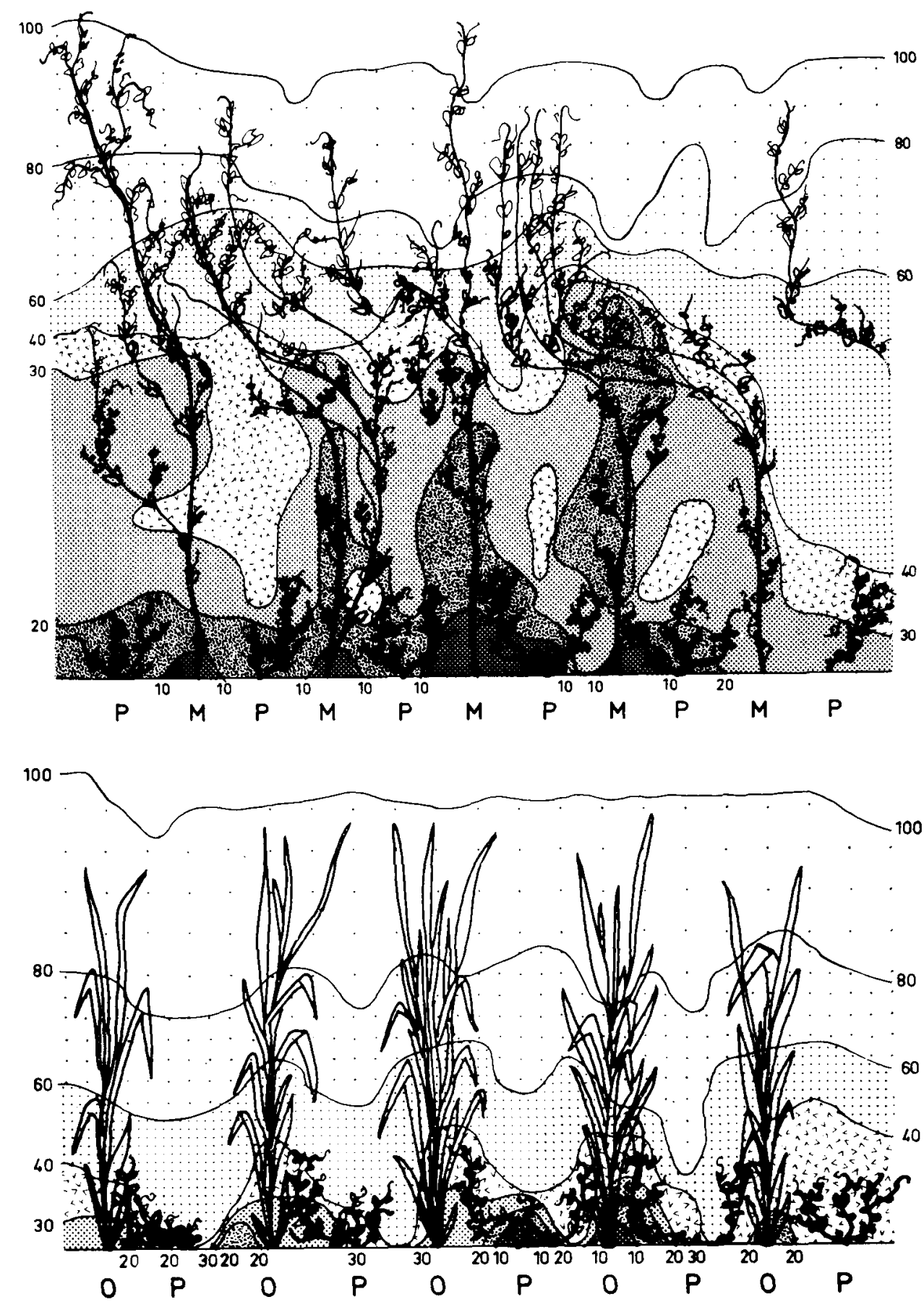

Fig. 8 Illumination in dependence of stand architecture in mixtures of long $(M)$ and short $(P)$ peas and of oats $(O)$ and short peas $(P)$. Illumination of a horizontal surface was measured with a selenium-cell from 10 to $10 \mathrm{~cm}$. The values are given in percent of the values above the stand. 
although at the last harvest the yield of barley was 1.6 times higher than the yield of oats.

The curves in Fig. $7 \mathrm{~b}$ present the percentage of light interception of the mixture of oats and small peas. The total interception again increased rapidly to a value near 90 percent. However, the trend in the interception of the individual components of the mixture are completely different. At an earlier stage short peas intercepted about 30 percent of the light, whereas oats intercepted about 50 percent. But from then on the oats increased in length up to $90 \mathrm{~cm}$ and the short peas stayed at $40 \mathrm{~cm}$ which resulted in a sharp decrease in light interception by the short peas and a concurrent increase in that of the oats. Fig. $7 \mathrm{c}$ shows that oats and long peas are also subjected to a redistribution of light, although the pattern is less clear-cut in this case.

The leaves of long and short peas are so alike, that it was impossible to measure the percentage light interception of both species separately in the field. However, this was possible under greenhouse conditions and the results in Fig. $7 \mathrm{~d}$ show that in this case also a redistribution of light took place. The degree of shading of the short peas by the long peas or oats is also illustrated in Fig. 8, where the relative light extinction is given in relation to the architecture of a mixed stand.

The above observations show that the calculation according to equations (9) hold only for mixtures like those of barley and oats, because their growth in height is such, that they cannot encroach upon the light space once occupied by the other. On the other hand it is clear that the short peas in mixture with long peas or with oats yield less than calculated according to equation (9) (Fig. 4a, b, c) because the latter species encroach upon the light space, occupied by the first in an earlier stage.

\section{An approximate calculation of the mutual interference of crops of different heights}

The equations (9) are transformed in order to arrive at an approximate method to account for differences in height. At first the increase in relative space from time $t$ to time $(t+\triangle t)$ is obtained:

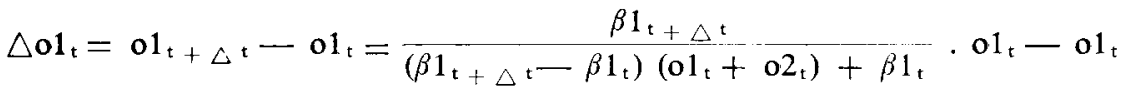

$$
\begin{aligned}
& =\Delta \beta 1_{1}-\frac{1}{\Delta \beta 1_{\mathrm{t}}\left(\mathrm{o} 1_{\mathrm{t}}+\mathrm{o} 2_{\mathrm{t}}\right)}+\beta 1_{\mathrm{t}}\left(1-\mathrm{o} 1_{\mathrm{t}}-\mathrm{o} 2_{\mathrm{t}}\right) \mathrm{o} 1_{\mathrm{t}}
\end{aligned}
$$

in which $\triangle \beta_{\mathrm{t}}$ is $\beta_{\mathrm{t}}+\Delta \mathrm{t}-\beta_{\mathrm{t}}$. Now the rate of change of the relative space at time $\mathrm{t}$ is obtained by dividing this difference by $\triangle t$ and taking the limiting value for $\Delta t$ approaching zero. This yields:

$$
\begin{aligned}
& \left(\frac{\mathrm{dol}}{\mathrm{dt}}\right)_{\mathrm{t}}=\operatorname{Lim}_{\triangle \mathrm{t} \rightarrow \mathrm{O}}\left(\frac{\triangle \mathrm{o} 1_{\mathrm{t}}}{\Delta \mathrm{t}}\right)= \\
& =\operatorname{Lim}_{\Delta \mathrm{t} \rightarrow \mathrm{o}}\left\{\frac{\Delta \beta 1_{\mathrm{t}}}{\Delta \mathrm{t}} \cdot \frac{1}{\Delta \beta 1_{\mathrm{t}}\left(\mathrm{o} 1_{\mathrm{t}}+\mathrm{o} 2_{\mathrm{t}}\right)+\beta 1_{\mathrm{t}}} \cdot\left(1-\mathrm{o} 1_{\mathrm{t}}-\mathrm{o} 2_{\mathrm{t}}\right) \mathrm{o} 1_{\mathrm{t}}\right\}= \\
& =\mathrm{r} 1_{\mathrm{t}}\left(1-\mathrm{o} 1_{\mathrm{t}}-\mathrm{o} 2_{\mathrm{t}}\right) \mathrm{o} 1_{\mathrm{t}}
\end{aligned}
$$


in which

$$
\mathbf{r} \mathbf{l}_{\mathrm{t}}=\left(\frac{\mathrm{d} \beta 1 / \beta 1}{\mathrm{dt}}\right)_{\mathrm{t}}
$$

is the relative rate of increase in $\beta 1$.

Apart from two differences, this differential equation corresponds to the one introduced by Volterra (1928). The relative rate of increase $\left(r_{t}\right)$ is here a variable function of time, whereas Volterra supposed that $r_{t}$ was a constant function of time. This latter supposition, which in most situations is a very unrealistic one, was also made by Shinozaki and Kira (1956), probably because only on this basis some analytical solutions for the differential equation (16) can be found.

It was realized by Volterra that under many conditions two species do not feel each other's presence in the same way and to account for this he introduced two other constants which transform equation 17 into:

$\left(\frac{\mathrm{dol}}{\mathrm{dt}}\right)_{\mathrm{t}}=\mathrm{rl}_{\mathrm{t}} \mathrm{H} 1_{\mathrm{t}}-\frac{\mathrm{H} 1_{\mathrm{t}} \cdot \frac{\mathrm{o} 1_{\mathrm{t}}}{\mathrm{H} 1_{\mathrm{t}}}-\mathrm{H} 2_{\mathrm{t}} \cdot \mathrm{o} 2_{\mathrm{t}}}{\mathrm{o} 1_{\mathrm{t}}}$

Both species feel each others presence in the same way as their own, if the interference factors $\mathrm{H} 1$ and $\mathrm{H} 2$ are the same. However, when at time the value of $\mathrm{H}_{2}$ is two times larger than $\mathrm{H} 1$, the first species feels the presence of the second one with a two times higher effect than its own presence, whereas the inverse occurs for the other species. It has been shown that the equations (9) hold when both species have about the same height during the growing period, so that in first approximation it may be tried to substitute for the value of $\mathbf{H}$ the height of the species which transforms the equations (9) into:

$$
\begin{aligned}
& \mathrm{o} 1_{1+1}=-\frac{1}{\left(\beta 1_{\mathrm{t}+1}-\beta 1_{\mathrm{t}}\right)} \begin{array}{c}
\boldsymbol{H} 1_{\mathrm{t}} 1_{\mathrm{t}} \cdot \mathrm{o} 1_{\mathrm{t}}+\mathrm{H} 2_{\mathrm{t}} \cdot \mathrm{o} 2_{\mathrm{t}}+\beta 1_{\mathrm{t}} \\
\mathrm{H} 1_{\mathrm{t}}
\end{array} \\
& \mathrm{o} 2_{\mathrm{t}+1}=\frac{\beta 2_{\mathrm{t}}+1}{\left(\beta 2_{\mathrm{t}+1}-\beta 2_{\mathrm{t}}\right) \frac{\mathrm{H} 2_{\mathrm{t}} \cdot \mathrm{o} 2_{\mathrm{t}}+\mathrm{H} 1_{\mathrm{t}} \cdot \mathrm{o} 1_{\mathrm{t}}}{\mathrm{H} 2_{\mathrm{t}}}+\beta 2_{\mathrm{t}}} \mathrm{o} 2_{\mathrm{t}}
\end{aligned}
$$

Of course this should be done only from the time that the species shade each other or when both species intercept about 90 percent of the light which occurs at a total weight of about $2000 \mathrm{~kg}$ dry matter/ha. Again the calculation is easily done in a step by step procedure. On each day the total yield is calculated. As long as this yield is below $2000 \mathrm{~kg} /$ ha the value of 1 is substituted for $\mathbf{H} 1$ and $\mathrm{H} 2$. Thereafter the heights of the crops on the appropriate day are read from curves in Fig. 6 and substituted in equation (19) along with the values of the other data. There is no reasonable base for the introduction of any refinements in the transition zone. The results are presented in Fig. 9a, b, c and d by the dotted lines. The calculations, taking into account the height of the crop, in case of the barley-oats mixture show not such good results as the former calculations, but the overall improvement in mixtures with oats, short peas and long peas is considerable. 

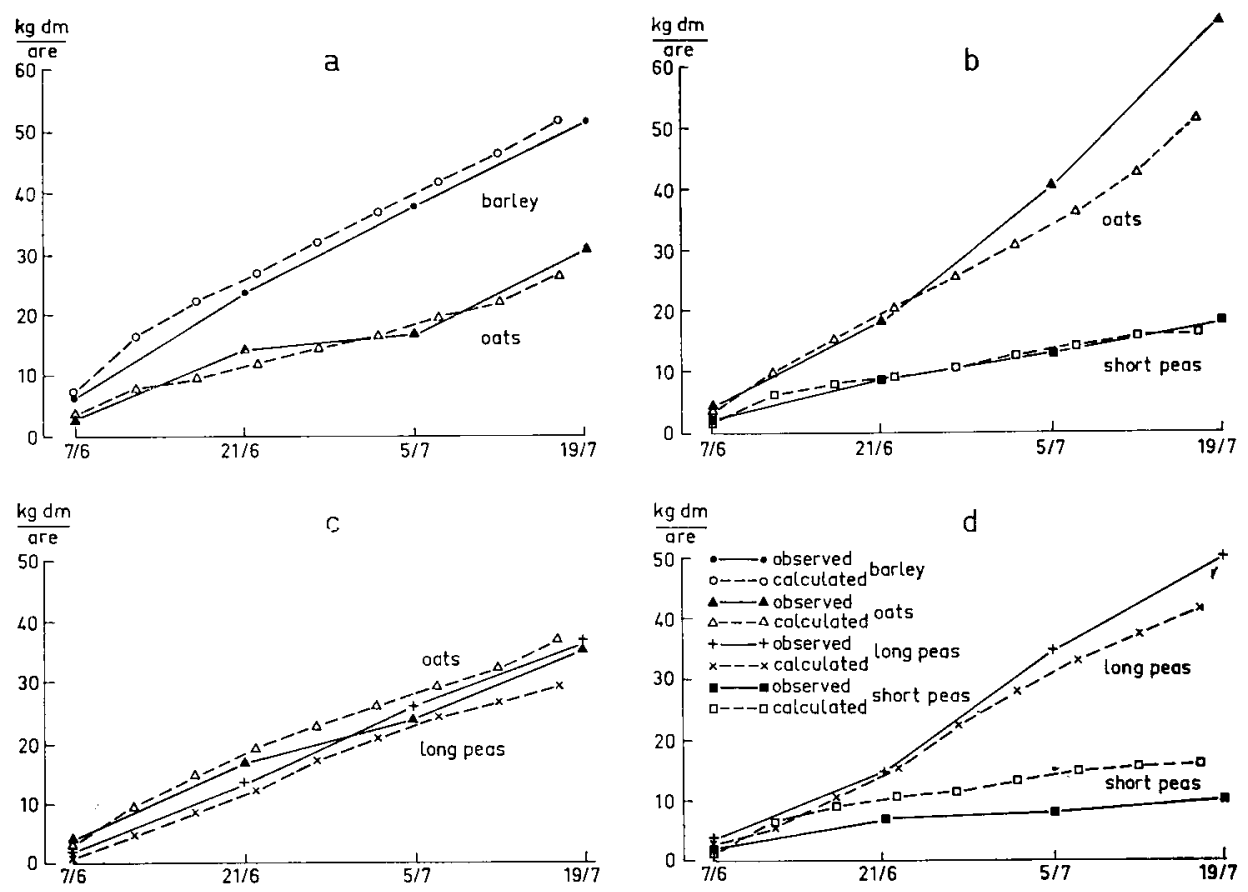

Fig. 9 Calculated (eq. 19) and observed yields of barley, oats, long peas and short peas in mixtures. Field experiment 1966.

Hence, when it is known, that the nutrient and water supply is sufficient, the present method forms a reasonable base to calculate the mutual interference of two species based on their growth in monoculture and the more so the more alike the species will be with respect to their height.

Calculations based on field experiments in 1960-1964 (see appendix 4) with oats and barley or oats and short peas are presented in Fig. 10a-d. Since height measurements were not available, the calculations were based on equation (9) only. Like in 1966, the actual performance of the short peas in mixture with oats (Fig. 10a and b) was far less than the calculated performance. This can be attributed safely to the difference in height and the encroachment of the longer species upon the light space of the shorter one. The calculated and observed results for the mixture of barley and oats (Fig. 10c and d) agree fairly in 1960, but differ in 1961. Although height measurements are not available, it is unlikely that such large differences can be attributed to an encroachment of oats upon the light space of barley, so that some other form of encroachment has to be assumed. This shows, that these calculations based on measurements in monocultures are useful within limits only. In every case it is prudent to incorporate one mixture into the experiment enabling to check on the extrapolation to mixed cultures. If the calculated and observed growth curves in one mixture agree sufficiently for the problem at hand, the extrapolation to other mixtures may be trusted. 

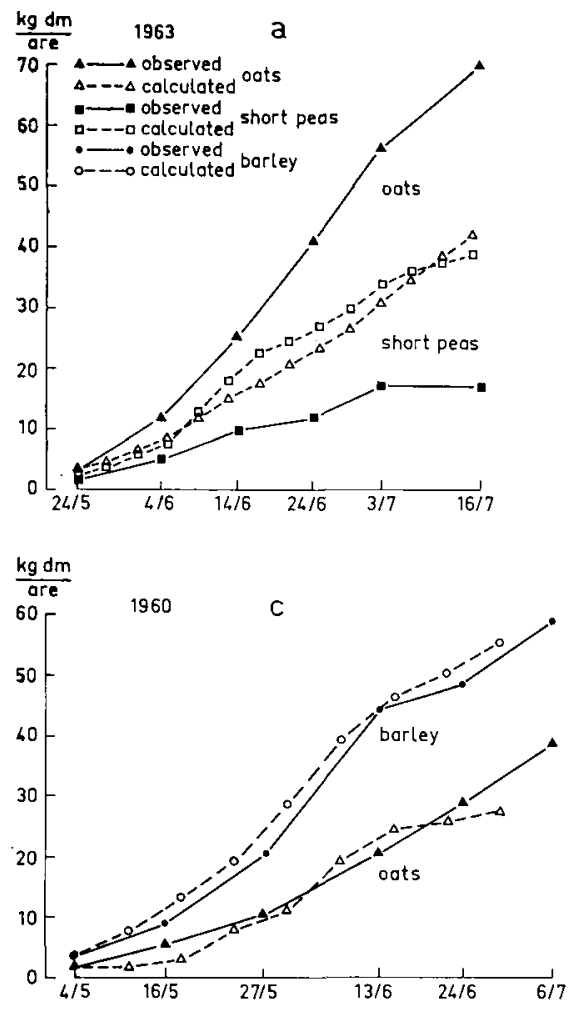
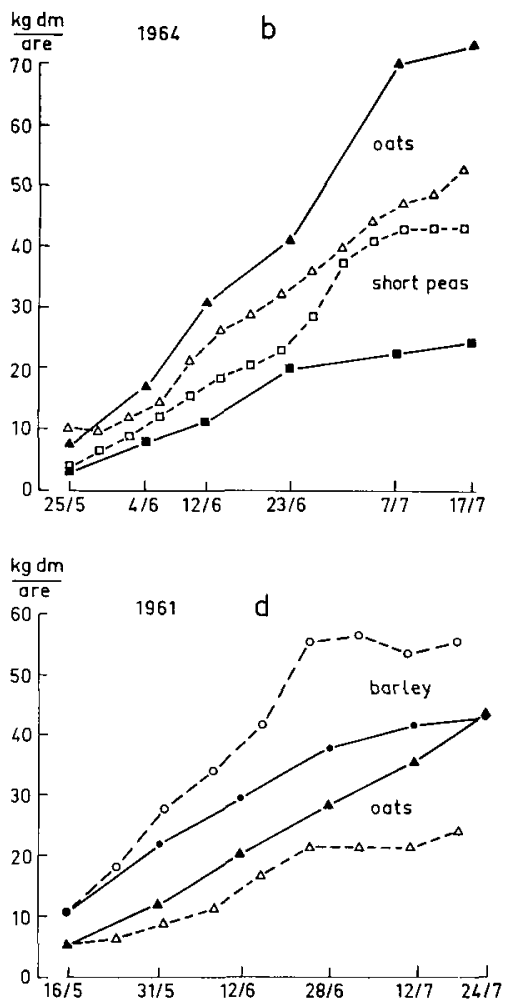

Fig. 10 Calculated (eq. 9) and observed yields of oats and barley and of oats and short peas in mixtures. Field experiments 1960, 1961, 1963 and 1964.

\section{Computation of the interference factors out of experimental data}

If the ratio $\mathrm{H} 1 / \mathrm{H} 2$ in equation (19) cannot be estimated from height measurements, it should be possible to estimate these directly from the growth curves of the species in mixture and in monoculture.

For this purpose the equations (19a) and (19b) are rearranged with the value of $\mathrm{H} 1 / \mathrm{H} 2$ explicitely:

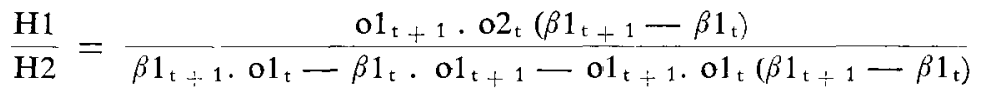

and a similar equation for $\mathrm{H} 2 / \mathrm{H} 1$.

All values at the right hand side of these equations are now known. The values of $\beta$ can be read from the curves in Fig. 2 and the values of $o$ can be calculated by dividing the yields of the species in the mixture at these times by the appropriate values of the maximum yield, $\Omega$, as obtained from the curves in Fig. 2 .

It appears, however, that the absolute values of the products in the numerator and 
denominator are about 10 times larger than the numerator and denominator itself, so that the accuracy of both values is far too low to calculate $\mathrm{H} 1 / \mathrm{H} 2$.

\section{Appendix 1. Field experiment 1966}

The experiment IBS 975 involved monocultures and two-component-mixtures of barley (variety Impala), oats (var. Astor), short peas (var. Pauli), and long peas (var. Mechelse Krombek). On the 2nd of May 1966 the monocultures were sown at two spacings, i.e. with row distances of $100 \mathrm{~cm}$ and $25 \mathrm{~cm}$, respectively. In mixtures the two species were sown in alternate rows with a row distance of $25 \mathrm{~cm}$, i.e. $50 \mathrm{~cm}$ row distance between rows of the same species. Each set of treatments was replicated 16 times, in order to enable 4 pediodic harvests with 4 replicates each.

The growth of long peas was supported by wire gauze of $120 \mathrm{~cm}$ height in rows of $50 \mathrm{~cm}$ row distance. The crops were kept free of weeds by applying a pre-emergence herbicide and later by clean weeding. The soil of the experimental site in Oostelijk Flevoland Polder, the Netherlands, was a heavy but well structured clay, containing $10.6 \% \mathrm{CaCO}_{3}$ and $4.6 \%$ organic matter. Kalium being abundant in the soil, only phosphate $\left(120 \mathrm{~kg} / \mathrm{ha} \mathrm{P}_{2} \mathrm{O}_{5}\right)$ and nitrogen $(90 \mathrm{~kg} / \mathrm{ha} \mathrm{N})$ were supplied at the time of sowing. The amount of precipitation from 1.5.-20.7.1966 was $343 \mathrm{~mm}$, so that the water supply of the plants was ample.

Total dry matter of each crop species (stubble and roots excluded) were measured repeatedly during the growing period, starting as soon as the growth of the stands became density dependent. Table 1 gives the yield data.

\section{Appendix 2. Greenhouse experiment 1966}

Long peas (Mechelse Krombek) and short peas (Pauli) were grown in containers of $182 \mathrm{l}$, filled with sand. The pH-value (water) of the soil was 5.7, and limestone

Table 1 Mean yield ( $\mathrm{kg}$ dry matter $/ 100 \mathrm{~m}^{2}$ ) in field experiment IBS 975, 1966

\begin{tabular}{|c|c|c|c|c|c|c|c|c|}
\hline \multirow{3}{*}{$\begin{array}{l}\text { Date of } \\
\text { harvesting }\end{array}$} & \multirow{2}{*}{\multicolumn{2}{|c|}{ barley }} & \multicolumn{4}{|c|}{ Monocultures with row spacing $(\mathrm{cm})$} & & \\
\hline & & & \multicolumn{2}{|c|}{ oats } & \multicolumn{2}{|c|}{ long peas } & \multicolumn{2}{|c|}{ short peas } \\
\hline & 25 & 100 & 25 & 100 & 25 & 100 & 25 & 100 \\
\hline 7 June & 11.7 & 3.6 & 8.1 & 2.2 & 6.0 & 1.5 & 5.2 & 1.2 \\
\hline 21 June & 42.6 & 22.3 & 31.9 & 14.2 & 26.2 & 9.5 & 24.0 & 8.9 \\
\hline 19 July & 58.8 & 34.1 & 50.3 & 26.3 & 48.5 & 23.2 & 44.5 & 19.7 \\
\hline \multirow[t]{3}{*}{19 July } & 85.8 & 49.6 & 78.9 & 51.6 & 60.5 & 36.1 & 64.7 & 31.1 \\
\hline & \multicolumn{6}{|c|}{ Mixtures } & & \\
\hline & \multicolumn{2}{|c|}{ barley _ oats } & oats & $\begin{array}{l}\text { long } \\
\text { peas }\end{array}$ & oats & $\begin{array}{l}\text { short } \\
\text { peas }\end{array}$ & $\begin{array}{l}\text { long } \\
\text { peas }\end{array}$ & $\begin{array}{l}\text { short } \\
\text { peas }\end{array}$ \\
\hline 7 June & 6.2 & 3.0 & 4.1 & 2.8 & 4.1 & 2.3 & 2.9 & 1.6 \\
\hline 21 June & 23.5 & 14.2 & 16.8 & 13.3 & 18.7 & 9.0 & 14.7 & 6.8 \\
\hline 5 July & 37.5 & 16.5 & 23.5 & 25.2 & 40.1 & 12.6 & 34.7 & 7.6 \\
\hline 19 July & 51.2 & 30.8 & 35.5 & 36.7 & 68.7 & 18.5 & 50.0 & 10.0 \\
\hline
\end{tabular}


was added to achieve a pH-value of 6.5. Fertilizers were added in amounts of $0.22 \mathrm{~g}$ $\mathrm{P}_{2} \mathrm{O}_{5}, 0.27 \mathrm{~g} \mathrm{~K} \mathrm{~K}_{2} \mathrm{O}$ and $0.138 \mathrm{~g} \mathrm{~N}$ per $\mathrm{kg}$ soil. The plants were watered by subirrigation, keeping the water table constant at a depth of $30 \mathrm{~cm}$.

Both species were cultivated in monocultures and mixed cultures with species in alternate rows. One set of treatments contained a separation of the root systems between each row of plants by a plastic sheet. Each treatment had four replicates.

The experiment was started on 29 August and finally harvested on 26 October. The results bave been given in the main section (Fig. 5).

\section{Appendix 3. Estimation of the relative light interception by the species in a mixed stand}

The amount of light intercepted by a leaf canopy may be determined by light measurements above and in the canopy. However, such measurements do not give any information about the distribution of light over the leaves of the various species which form the canopy. This distribution may be estimated by looking at the canopy and recording the relative frequency of the leaves of the various species that can be seen from various angles.

A simple viewer was constructed for this purpose. As demonstrated in Fig. 11, this viewer consists of a tube of about $20 \mathrm{~cm}$ length and $2 \mathrm{~cm}$ width, with a crosswire attached to the open end and a small hole at the other end of the tube. This camera obscura principle causes loss of brightness, but enables the observer to see object and crosswire with equal sharpness, independent of the distance between object and eye. Any object, either plant species or bare soil, which is covered by the crosswire can be identified. A needle, connected with the tube indicates on a scale on which the angle of inclination of the tube at the time of observation can be read. The attached scale is kept in position by gravity. Observations have to range over all possible angles of inclination $(\alpha)$ and azimuth $(\beta)$, because the species are of different architecture and cultivated in rows. Geometrically, it does not make any difference whether the observations are taken by aiming at a fixed point in the canopy and moving the position of the observer, or by fixing the position of the observer and aiming

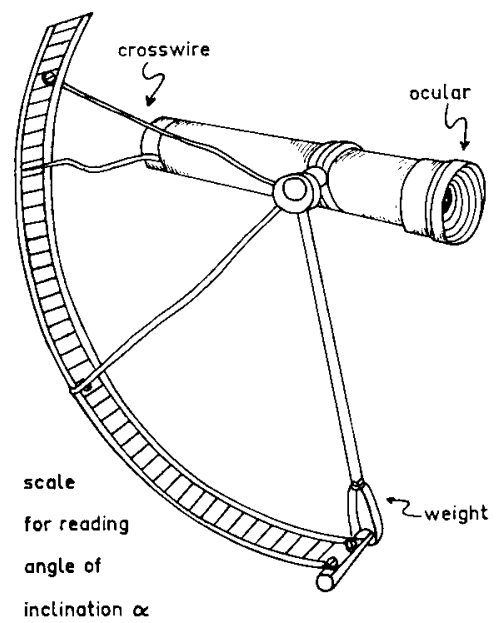

118
Fig. 11 Implement for measuring the relative light interception by species in a mixed stand. 

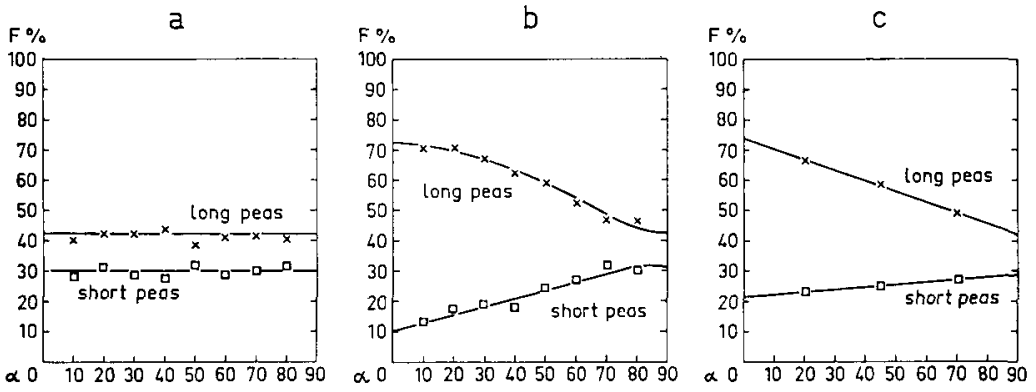

Fig. 12 Relative light interception $(F)$ by long peas and short peas in dependence of the angle of inclination (a). Parallel to the rows (a), perpendicular to the rows (b) and averaged for regular intervals of the azimuth angle. Greenhouse experiment 1966.

at various points in the canopy, but the latter method of course gives the best averages and is the most convenient.

The values of $\beta$ were chosen by turning the viewer around the axis of the observer at an even pace and counting the various objects covered by the crosswire at about equal time intervals. Any bias, caused by growing the species in alternate rows was eliminated by changing systematically the place from which observations were taken. The relative frequency $(F)$ for each species and the soil at a given value of $\alpha$ is calculated with:

$$
F_{i}=\frac{S_{i}}{S_{1}+S_{2}+S_{3}} \quad(i=1,2,3)
$$

in which $S_{1}, S_{2}$ and $S_{3}$ are the number of times that species 1 , species 2 and the soil surface were observed. Each mean value of $F$ was based on 1200 observations each, this being the sum of four replicated observation series within each plot, replicated on four different plots.

Some values of F, obtained for the greenhouse experiment with mixed culture of long and short peas (Mechelse Krombek and Pauli, respectively), are used to demonstrate the influence of inclination $(\alpha)$ and the azimuth $(\beta)$ on $\mathrm{F}$. In Fig. 12a-c, $\mathrm{F}$ is given as a function of $\alpha$ with extrapolated values for $\alpha=0$ and $90^{\circ}$. The values of $\mathrm{F}$ are independent of $\alpha$ when the observations are taken parallel to the rows at $\beta=0^{\circ}$ (Fig. 12a), but with observations perpendicular to the rows at $\beta=90^{\circ}$, the curves for $F$ differ according to the heights of the species in the mixture (Figure $12 \mathrm{~b}$ ). The extrapolated values of $\mathrm{F}$ at $\alpha=90^{\circ}$ should be independent of $\beta$, so that these can be used as a control. Fig. 12c shows that a curve drawn through three points provides a fair estimate, so that measurements in the field were restricted to the three angles of inclination $20^{\circ}, 45^{\circ}$ and $70^{\circ}$.

To obtain the average relative light interception from these measurements, it has to be taken into account that various sections of the sky contribute with different amounts to the illumination of an horizontal surface. The relative contribution of each section in case of uniform brightness of the sky $(R)$ is given by the first row of numbers in Table 2. However, it has to be considered also that the brightness distribution along the sky depends on solar altitude and cloudiness. Table 2 contains also the 
Table 2 The relative contribution to the illuminance of a horizontal surface of 10 degree zones from a sky with uniform brightness $(C)$ and the relative brightness of these zones in respect to the brightness of the zenith $(B)$ for various conditions of the sky. Sources: De Wit, 1965; Dogniaux, 1954; Jones and Condit, 1948

\begin{tabular}{|c|c|c|c|c|c|c|c|c|c|c|c|}
\hline & \multirow{2}{*}{$\begin{array}{c}\text { Solar } \\
\text { altitude }\end{array}$} & \multicolumn{10}{|c|}{ Inclination } \\
\hline & & 0 & 10 & 20 & 30 & 40 & 50 & 60 & 70 & 80 & 90 \\
\hline C & & & 0030 & .0087 & .0133 & .0163 & .0174 & .0163 & .0133 & .0087 & .0030 \\
\hline \multicolumn{12}{|c|}{ B (skylight only) } \\
\hline clear sky & $40^{\circ}$ & & 2.84 & 2.49 & 2.24 & 2.09 & 1.76 & 1.40 & 1.21 & 1.12 & 1.07 \\
\hline overcast & $40^{\circ}$ & & 1.29 & 1.46 & 1.56 & 1.61 & 1.53 & 1.29 & 1.10 & 1.04 & 1.02 \\
\hline clear sky & $20^{\circ}$ & & 7.07 & 5.81 & 4.40 & 2.90 & 1.97 & 1.47 & 1.20 & 1.12 & 1.05 \\
\hline clear sky & $60^{\circ}$ & & 1.26 & 1.08 & .98 & 1.00 & 1.15 & 1.16 & 1.10 & 1.03 & 1.02 \\
\hline
\end{tabular}

relative brightness of the sections in respect to the brightness of the zenith for various sky conditions (B) according to measurements of Dogniaux (1954) and Jones and Condit (1948).

The relative light interception by a species can now be estimated by:

$\mathbf{R L I}=\Sigma \frac{\mathbf{R} \cdot \mathbf{B}}{\Sigma(\mathbf{R} \cdot \mathbf{B})} \mathbf{F}$

the summing being done for the average of $10^{\circ}$ altitude sections.

Calculations have been carried out for the various values of $B$ in Table 2, but it appeared that the differences are small compared to the difference between species. Therefore all calculations were done with the data for an overcast sky with a solar altitude of $40^{\circ}$. Although this might be possible in principle, (compare De Wit, 1965) it was assumed not to be worthwhile to take the direct light of the sun and the movement of the sun along the sky into account.

The relative light interception data, calculated in the above way are presented in the Fig. $7 \mathrm{a}-\mathrm{d}$.

\section{Appendix 4. Field experiments in $1960-1964$}

Following the same experimental procedure as described for the field trial in 1966, two experiments were done in 1960 and 1961 with barley (variety Herta) and oats (var. Marne) and another set of experiments in 1963 and 1964 with oats (var. Marne) in combination with short peas (var. Pauli). The row distances of the monocultures were 100 and $25 \mathrm{~cm}$; in the mixtures the species were sown in alternate rows with a row distance of $25 \mathrm{~cm}$.

The soil of the experimental field near Wageningen, the Netherlands, was sand with a $\mathrm{pH}$-value of 4.9 and a content of organic matter of $3.8 \%$. The field was fertilized with $90 \mathrm{~kg} / \mathrm{ha} \mathrm{K}_{2} \mathrm{O}, 96 \mathrm{~kg} / \mathrm{ha} \mathrm{P}_{2} \mathrm{O}_{5}$ and $46-76 \mathrm{~kg} / \mathrm{ha} \mathrm{N}$. The homogeneity of the soil in this field was lacking, so considerable scattering of the yield data was observed. Tables 3a-d give the yields of periodic harvests, i.e. the total dry matter without stubble and roots, for each experiment. 
COMPETITIVE INTERFERENCE OF PLANT SPECIES IN MONOCULTURES AND MIXED STANDS

Table $3 a$ Mean yield ( $k g$ dry matter $/ 100 \mathrm{~m}^{2}$ ) in field experiment IBS 361,1960

\begin{tabular}{|c|c|c|c|c|c|c|}
\hline \multirow[t]{3}{*}{$\begin{array}{l}\text { Date of } \\
\text { harvesting }\end{array}$} & \multicolumn{4}{|c|}{$\begin{array}{l}\text { Monocultures with } \\
\text { row spacing }(\mathrm{cm})\end{array}$} & \multicolumn{2}{|c|}{ Mixture } \\
\hline & \multicolumn{2}{|c|}{ barley } & \multicolumn{2}{|c|}{ oats } & \multirow[t]{2}{*}{ barley } & \multirow[t]{2}{*}{ oats } \\
\hline & 25 & 100 & 25 & 100 & & \\
\hline 4 May & 5.3 & 1.6 & 3.5 & 0.9 & 3.3 & 2.1 \\
\hline $16 \mathrm{May}$ & 20.0 & 7.2 & 11.8 & 3.5 & 9.3 & 5.4 \\
\hline 27 May & 34.6 & 13.8 & 20.4 & 6.8 & 20.5 & 10.4 \\
\hline 13 June & 73.5 & 35.2 & 60.2 & 29.4 & 44.4 & 20.9 \\
\hline 24 June & 79.4 & 39.9 & 72.3 & 41.1 & 48.2 & 29.0 \\
\hline $6 \mathrm{July}$ & 93.6 & 49.5 & 83.0 & 42.0 & 59.0 & 39.2 \\
\hline
\end{tabular}

Table 36 Mean yield ( $k g$ dry matter $/ 100 \mathrm{~m}^{2}$ ) in field experiment IBS 479, 1961

\begin{tabular}{|c|c|c|c|c|c|c|}
\hline \multirow[t]{3}{*}{$\begin{array}{l}\text { Date of } \\
\text { harvesting }\end{array}$} & \multicolumn{4}{|c|}{$\begin{array}{l}\text { Monocultures with } \\
\text { row spacing }(\mathrm{cm})\end{array}$} & \multicolumn{2}{|c|}{ Mixture } \\
\hline & \multicolumn{2}{|c|}{ barley } & \multicolumn{2}{|c|}{ oats } & \multirow[t]{2}{*}{ barley } & \multirow[t]{2}{*}{ oats } \\
\hline & 25 & 100 & 25 & 100 & & \\
\hline $16 \mathrm{May}$ & 17.3 & 6.4 & 12.1 & 3.1 & 10.6 & 5.3 \\
\hline 31 May & 44.1 & 16.6 & 31.4 & 10.4 & 22.2 & 12.3 \\
\hline 12 June & 56.1 & 24.0 & 44.4 & 19.2 & 29.8 & 20.3 \\
\hline 28 June & 75.3 & 42.1 & 61.1 & 39.2 & 37.8 & 28.7 \\
\hline I2 July & 86.7 & 53.0 & 74.2 & 47.8 & 41.6 & 35.2 \\
\hline 24 July & 82.3 & 61.9 & 88.9 & 59.9 & 42.7 & 43.0 \\
\hline
\end{tabular}

Table 3c Mean yield ( $\mathrm{kg}$ dry matter/100 $\mathrm{m}^{2}$ ) in field experiment IBS 729,1963

\begin{tabular}{|c|c|c|c|c|c|c|}
\hline \multirow[t]{3}{*}{$\begin{array}{l}\text { Date of } \\
\text { harvesting }\end{array}$} & \multicolumn{4}{|c|}{$\begin{array}{l}\text { Monocultures with } \\
\text { row spacing }(\mathrm{cm})\end{array}$} & \multicolumn{2}{|c|}{ Mixture } \\
\hline & \multicolumn{2}{|c|}{ oats } & \multicolumn{2}{|c|}{ short peas } & \multirow[t]{2}{*}{ oats } & \multirow[t]{2}{*}{ short peas } \\
\hline & 25 & 100 & 25 & 100 & & \\
\hline 24 May & 6.9 & 1.7 & 5.1 & 0.9 & 3.5 & 1.9 \\
\hline 4 June & 21.8 & 7.0 & 14.7 & 4.7 & 12.3 & 5.0 \\
\hline 14 June & 41.8 & 18.0 & 36.1 & 12.1 & 25.1 & 10.0 \\
\hline 24 June & 53.4 & 27.9 & 48.8 & 19.5 & 41.0 & 12.0 \\
\hline 3 July & 72.8 & 41.7 & 65.0 & 26.8 & 56.7 & 17.4 \\
\hline 16 July & 96.0 & 59.2 & 75.6 & 34.4 & 70.0 & 17.1 \\
\hline
\end{tabular}


Table 3d Mean yield ( $\mathrm{kg}$ dry matter $/ 100 \mathrm{~m}^{2}$ ) in field experiment IBS 814, 1964

\begin{tabular}{|c|c|c|c|c|c|c|}
\hline \multirow[t]{3}{*}{$\begin{array}{l}\text { Date of } \\
\text { harvesting }\end{array}$} & \multicolumn{4}{|c|}{$\begin{array}{l}\text { Monocultures with } \\
\text { row spacing }(\mathrm{cm})\end{array}$} & \multicolumn{2}{|c|}{ Mixture } \\
\hline & \multicolumn{2}{|c|}{ oats } & \multicolumn{2}{|c|}{ short peas } & \multirow[t]{2}{*}{ oats } & \multirow[t]{2}{*}{ short peas } \\
\hline & 25 & 100 & 25 & 100 & & \\
\hline 25 May & 20.2 & 5.1 & 9.4 & 2.5 & 7.9 & 3.7 \\
\hline 4 June & 28.6 & 9.9 & 22.1 & 6.2 & 17.3 & 8.0 \\
\hline 12 June & 49.8 & 18.4 & 36.4 & 12.2 & 31.1 & 11.2 \\
\hline 23 June & 63.6 & 30.6 & 56.6 & 20.7 & 41.6 & 20.2 \\
\hline 7 July & 94.3 & 43.4 & 94.4 & 38.8 & 70.3 & 22.7 \\
\hline 17 July & 102.4 & 57.4 & 94.6 & 40.5 & 73.3 & 24.9 \\
\hline
\end{tabular}

\section{Literature}

Anderson, M. C., 1964. Light reactions of terrestrial plant communities and their measurements. Biol. Rev., $39: 425-486$.

De Wit, C. T., 1960. On competition. Versl. Landbouwk. Onderz. 66.8.

De Wit, C. T., 1965. Photosynthesis of leaf canopies. Agric. Res. Rep. 663.

De Wit, C.T. and Van den Bergh, J. P., 1965. Competition between herbage plants. Neth. J. Agric. Sci,, 13: 212-221.

De Wit, C. T. and Ennik, G. C., 1958. Over concurrentie. Jaarboek I.B.S., Wageningen : 59-73.

Dogniaux, R., 1954. Etude des climate de la radiation en Belge. Bijdragen KMI, Ukkel, 18.

Donald, C. M., 1951. Competition among pasture plants. I. Intraspecific competition among annual pasture plants. Austral. J. Agric. Res., 2 : 355-376.

Donald, C. M., 1963. Competition among crop and pasture plants. Adv. Agronomy, 15: 1-118.

Holliday, R., 1960. Plant population and crop yield. Field Crop Abstr., 13: 159-167, 247-254.

Jones, L. A. and Condit, H. R., 1948. Sunlight and skylight as determinants of photographic exposure. I. Luminous density as determined by solar altitude and atmospheric conditions. J. Optical Soc. Amer., $38: 123-178$.

Kimball, H. K. and Hand, I. F., 1921. Sky-brightness and daylight-illumination measurements. Monthly Weather Rev., $49: 481-488$.

Shinozaki, K. and Kira, T., 1956. Intraspecific competition among higher plants. VII. Logistic theory of the C-D effect. J. Inst. Polytechnics, Series D (biology), $7:$ 35-72.

Tow, P. G., Ennik, G. C. and De Wit, C. T., 1966. Competition between legumes and grasses. Agric. Res. Rep. $687: 1-30$.

Volterra, V., 1928. Variations and fluctuations of the number of individuals in animal species living together. In: R. N. Chapman: Animal Ecology, New York, 1931. Original publication in: J. du Cons. int p. l'Expl. de la Mer. III, vol. 1. 